\title{
SHIN SPLINTS, OR STRESS FRACTURES OF THE METACARPAL BONE IN HORSES, AND SHIN SORENESS, OR STRESS FRACTURES OF THE TIBIA, IN MAN
}

\author{
M. B. Devas, hastings, England
}

From the Institute of Clinical Research, the Middlesex Hospital, London

There is a condition in horses known as splint disease, sore shins or bucked shins. I have been able to collect a series of five horses with this disease whose radiographs leave little doubt that it is a stress fracture. The clinical history resembles that found in stress fractures in man. The interest of the condition is that it is extraordinarily like the shin soreness of athletes caused by stress fracture of the tibia.

The horse, usually a yearling, goes lame and a swelling appears over the shin (Figs. 1 and 2). In the foreleg of the horse the shin is the second metacarpal bone; the third and fourth metacarpal bones are rudimentary and form the "splint bones" (Figs. 3 and 4). Because the callus from the stress fracture of the second metacarpal bone often lies under the medial splint bone, the latter is pushed in front of the callus so that, on clinical examination, it feels as though an "inflammation" of the splint bone causes the swelling. However, as shown clearly

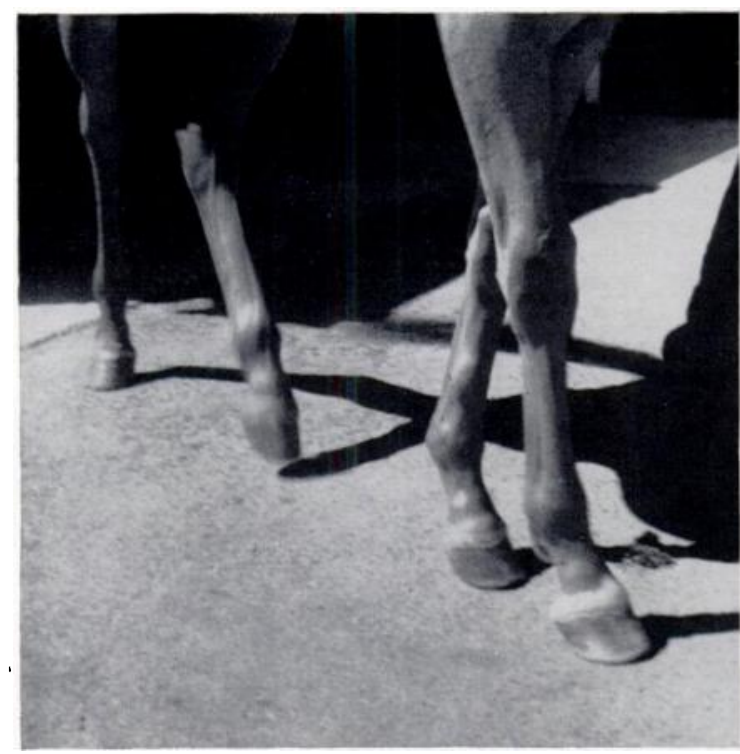

FIG. 1

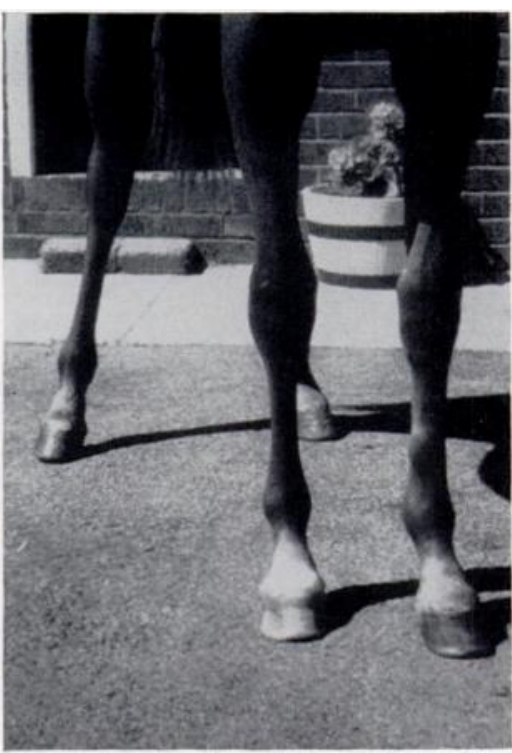

FIG. 2

Clinical photographs of the first horse in this series with splint disease. The swelling of the left shin on its medial aspect is clearly seen. The horse is taking weight on the affected limb.

in radiographs (Fig. 3), there can be no doubt that the second metacarpal bone has sustained an incomplete fracture. This oblique type of fracture through one cortex is typical of the stress fracture of the tibia seen especially in athletes. (Compare Figure 3 with Figure 5, which is the radiograph of an eighteen-year-old athlete with typical shin soreness (Devas 1958, Case 6).)

The oblique view of the same metacarpal bone of the same horse (Fig. 4) shows how the splint bone appears to be involved in the callus to an extent that would deceive the examining 


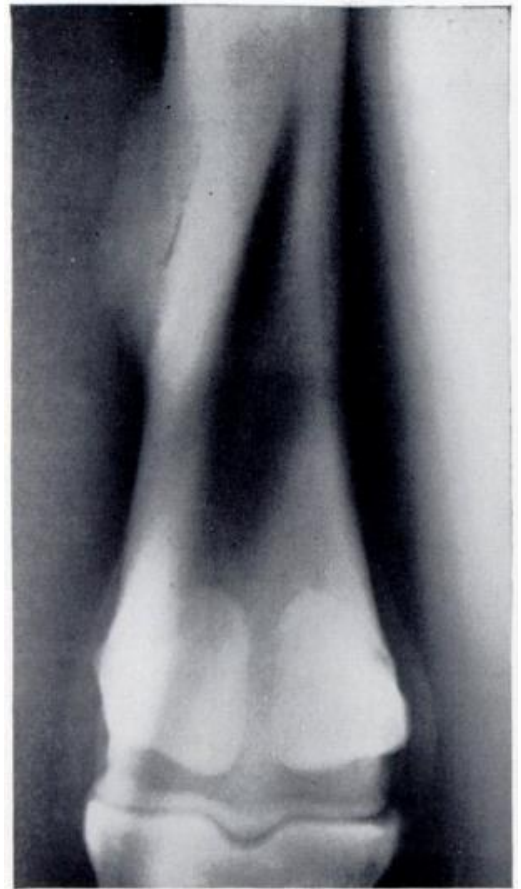

Fig. 3

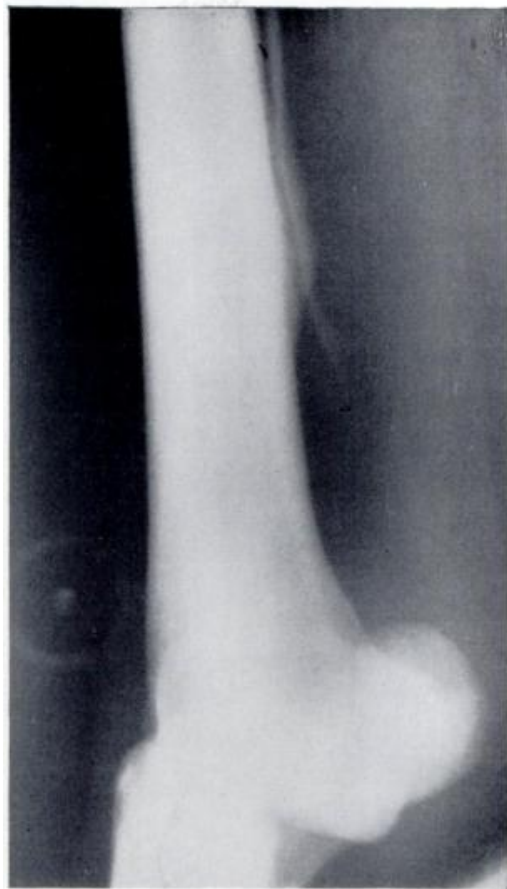

FiG. 4

Radiographs of the second metacarpal bone of the horse shown in Figures 1 and 2. Figure 3 shows the fracture line clearly, with the overlying callus that is causing the swelling seen and felt clinically. Figure 4 shows how the callus from the periosteal reaction of the second metacarpal bone appears to involve the splint bone, or first metacarpal remnant. It was this aspect of the condition that led to the idea that the splint bone was the site of the lesion.

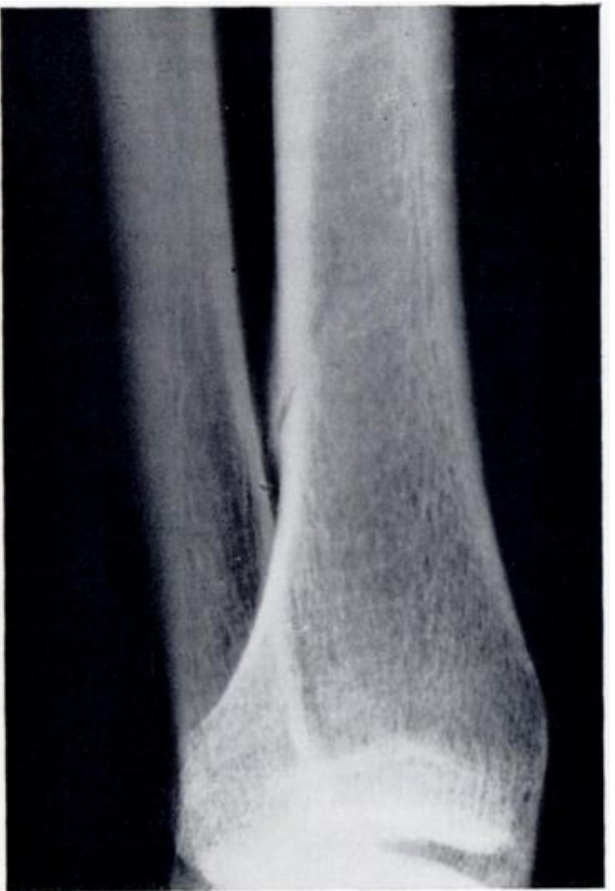

Fig. 5

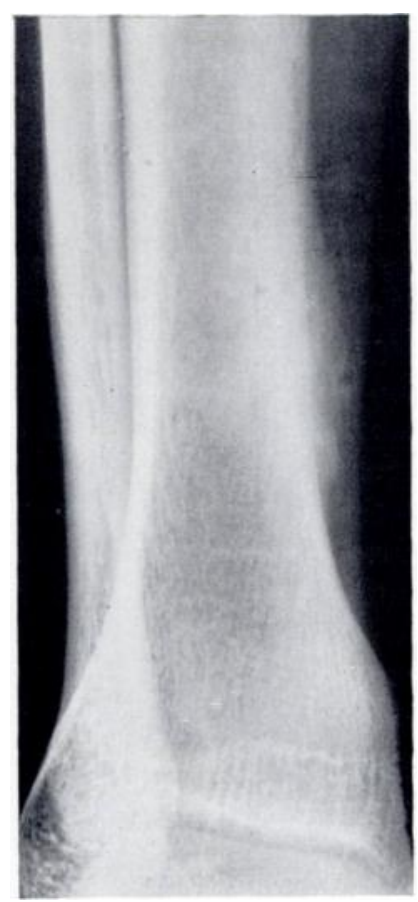

Fig. 6

Figure 5-Radiograph of the tibia of an athlete with shin soreness to show the fracture line and callus. It closely resembles that shown in Figure 3. Figure 6-An oblique view of the tibia of another athlete with shin soreness, to compare with Figure 4.

vol. 49 B, NO. 2, MAY 1967 
hand. However, the fuzzy nature of the callus is also seen in athletes. Figure 6 is a further example of this: in this oblique radiograph the callus on the athlete's shin can be seen, but the fracture line is invisible.

Radiographs good enough for reproduction are available in only three of the other four horses (Figs. 7 to 9); it is not easy to radiograph a high-spirited yearling without anaesthesia.

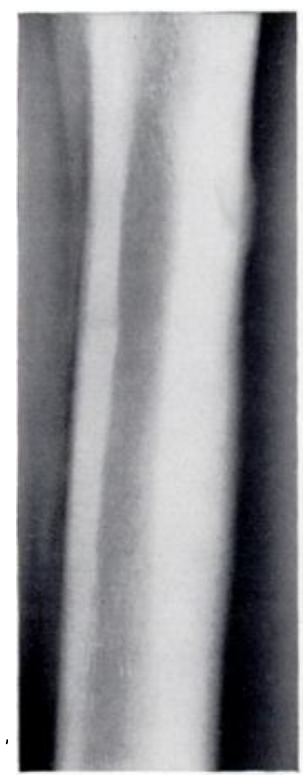

FIG. 7

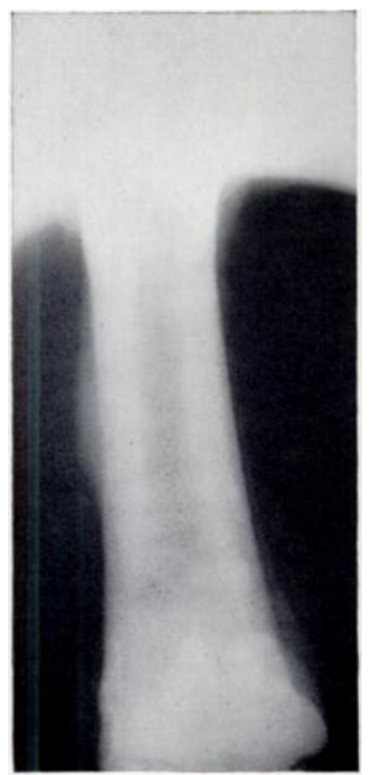

FIG. 8

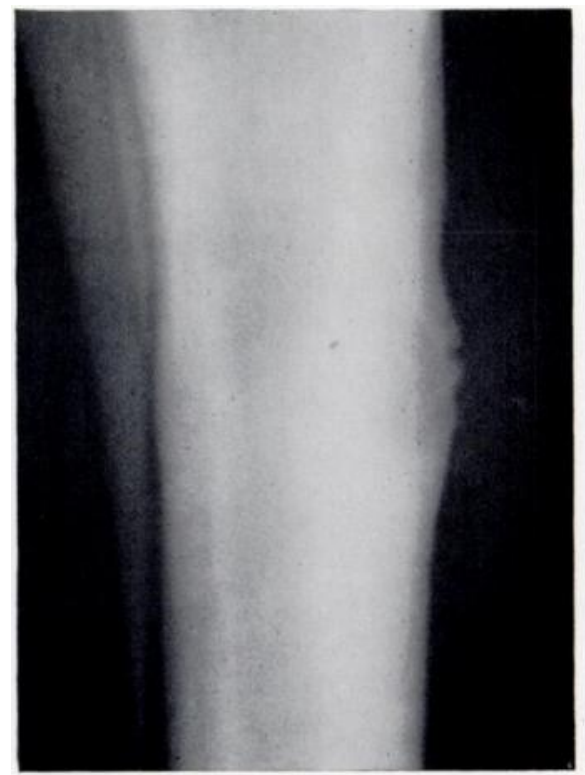

FIG. 9

Figure 7-The second horse in the series. The fracture line is incomplete, through one cortex only, and runs obliquely upwards and inwards. Figure 8 - The third horse shows periosteal callus typical of shin soreness as seen in the athlete. Figure 9-The fourth horse shows a later stage in the process of healing. The callus is eroded on its surface and is being absorbed.

Furthermore, this condition appears to attract little attention in veterinary practice as a whole and is accepted as a cause of lameness to be treated by time-honoured methods. Usually this means that the condition in horses, as in the athlete, causes great hardship, because it may prevent running for a whole season and may indeed deprive a potential champion of success.

\section{DISCUSSION}

Stress fractures have been described in animals, notably the greyhound (Bateman 1958, 1960; Devas 1961). Treatment by an endoprosthesis or fixation is sometimes successful and is used routinely for certain of these conditions (Bateman 1958). Another condition in horses, the split pastern, may well be the result of a stress fracture, comparable to the split tarsal navicular bone in greyhounds.

So far as is known, no operative treatment for splint disease in horses has been described, except cauterisation or other procedures designed to relieve an inflammatory condition. Although only five horses are reported here, the comparison with the tibial counterpart in athletes is so close that $I$ believe the diagnosis is the correct one in most, if not all, cases seen in horses. It must be said that not all veterinary surgeons with whom this has been discussed will agree with this diagnosis; and, of course, few horses have a routine radiographic examination for splint disease. The differential diagnosis of a stress fracture of the metacarpal bone of the horse includes direct injuries, exostoses which occur after torn lateral or medial ligaments, and inflammation from an infection. 
My interest in this condition in the horse is that it appears to be analogous to the same condition in the athlete. Shin splints in horses is an expensive disease because it necessitates long rest, and research on it might especially benefit racing stables. Moreover, because of the close comparison between the condition in horses and in the athlete, its study might also increase our knowledge of stress fractures in athletes. Further, because the horse has a long bone that sustains a stress fracture, it might be possible to determine the stresses and strains that occur in vivo under various conditions, and further research in this respect is planned.

\section{SUMMARY}

1. Shin splints in five horses is described as a stress fracture of the second metacarpal bone.

2. The value of this finding in relation to stress fracture of the tibia in man is discussed.

I am greatly indebted to Colonel John Hickman, School of Veterinary Medicine, Cambridge, for his advice, and I wish to thank Mr John K. Hooten of Hailsham, England, Professor F. J. Milne of Guelph, Ontario, Canada, and Dr James R. Rooney of Lexington, Kentucky, United States of America for the equine case notes and radiographs. I especially wish to thank Mr S. A. Jenkins of Eastbourne, England, who made the initial diagnosis of a stress fracture in horse 1.

\section{REFERENCES}

Bateman, J. K. (1958): Broken Hock in the Greyhound; Repair Methods and Plastic Scaphoid. Veterinary Record, 70, 621.

Bateman, J. K. (1960): Personal communication.

Devas, M. B. (1958): Stress Fractures of the Tibia in Athletes or "Shin Soreness." Journal of Bone and Joint Surgery, 40-B, 227.

Devas, M. B. (1961): Compression Stress Fractures in Man and the Greyhound. Journal of Bone and Joint Surgery, 43-B, 540. 